\title{
Self-Healing Polyurethane-Based Nanocomposites Modified with Carbon Fibres and Carbon Nanotubes
}

\author{
Szatkowski Piotr ${ }^{D}$, Pielichowska Kinga, and Blazewicz Stanislaw \\ Faculty of Materials Science and Ceramics, AGH University of Science and Technology, Al. Mickiewicza 30, 30-059 Krakow, Poland \\ Correspondence should be addressed to Szatkowski Piotr; pszatko@agh.edu.pl
}

Received 16 May 2020; Revised 17 August 2020; Accepted 22 August 2020; Published 30 August 2020

Academic Editor: Sagar Roy

Copyright (c) 2020 Szatkowski Piotr et al. This is an open access article distributed under the Creative Commons Attribution License, which permits unrestricted use, distribution, and reproduction in any medium, provided the original work is properly cited.

\begin{abstract}
Self-healing polyurethanes (PUs) were synthesized as a matrix of nanocomposites containing two fibrous carbon components, i.e., functionalized carbon nanotubes (CNF-OH) and short carbon fibers (CF). Two types of PUs differing in the content of flexible chain segments (40\% and 50\%) were used. Changes in mechanical strength were analyzed to assess the ability to self-healing of PU-based matrix nanocomposites with experimentally introduced damage in the form of an incision. The healing process was activated by heating the damaged samples at $60^{\circ} \mathrm{C}$, for 30 minutes. The addition of CNT-OH and CF caused a slight reduction in the self-healing ability of the nanocomposites as compared to the neat PUs. After heating to $60^{\circ} \mathrm{C}$, the nanocomposites selfhealed up to $72 \%$ of the initial strength of the undamaged samples. The introduction of fibrous components to the polymer matrix improved the thermal conductivity of nanocomposites and facilitated heat transfer from the environment to the interior of the samples, necessary to initiate self-healing. Low content of carbon components in the PU matrix, i.e., $3 \mathrm{wt} \%$ of CF and $2 \mathrm{wt} \%$ of CNF-OH increased the total work up to fracture of samples after healing by about $53 \%$.
\end{abstract}

\section{Introduction}

In recent years, more and more works have been devoted to the study of thermoplastic polymers as matrices for fibre reinforced composites [1-3]. Thermoplastics, in contrast to chemo and thermosetting polymers, can be reversibly mouldable. Composites made of thermoplastic matrices can be recycled by heating and moulded again from the recycled plastics. Other advantages of using thermoplastic matrices are the possibility of joining the composite elements by heating or adding a melted thermoplastics to elements of the mould. For these reasons, thermoplastic matrices including PUs are more and more frequently used in many industries such as automotive, construction, and sport [4-6]. They are used in the form of two-component mixtures, and the properties of the obtained materials depend on the ratio of isocyanate and polyol [7]. The use of such polymers as matrices in composite and nanocomposite technology creates new application possibilities in research on new types of materials [8]. Carbon fibres as components modifying the polyurethane matrix enhance the resistance to creep and fatigue, as well as increase the tensile strength and Young's modulus of the resulting composites [9-12]. Self-healing polymers are a new direction in the development of composites technology with such matrices.

This group of polymers includes self-healing duroplastic polymers (the healing agent is inside the material and is releasing to the site of the crack forming) [13-15], internal thermosets (the healing agent is dissolved in the matrix) [16], and thermoplastics with a regeneration system based on a physical or chemical self-healing mechanism [17].

Polyurethanes characterized by self-healing properties constitute a new area of research in composite technology. At present, the use of carbon fibres as reinforcement for such polymers is at the early stage of research and there are not many reports dealing with the subject [18-27]. Most published reports on PU self-regeneration concern the use of the reversible Diels-Adler reaction [28-30] or a description of the effectiveness of self-regeneration mechanisms of neat polyurethane matrices without fibrous modifiers [31-33].

Our previous study has shown that the addition of functionalized CNT to self-healing polyurethane caused a slight 
TABLE 1: Materials used for the preparation of PU-based nanocomposite samples.

\begin{tabular}{|c|c|c|c|c|}
\hline Name & Label & Agent & Manufacturer & Characteristics \\
\hline \multicolumn{5}{|l|}{ PU-based matrix } \\
\hline Polytetrahydrofuran & PTHF & Polyol & Sigma-Aldrich, Cat. no 345296 Germany & $\begin{array}{c}\text { Molar mass } \\
1000\end{array}$ \\
\hline Aliphatic isocyanate, & $\begin{array}{c}\text { HDI } \\
\text { derivative }\end{array}$ & Isocyanate & Desmodur $^{\circledR}$ N 3300 (Bayer) Germany & \\
\hline 1,4 Butanediol & $\mathrm{BDO}$ & Chain extender & Acros Belgium & \\
\hline Dibutyltin dilaurate & DBTDL & Catalyst & Sigma-Aldrich Germany & Organotin compound \\
\hline \multicolumn{5}{|l|}{ Carbon fibrous components } \\
\hline $\begin{array}{l}\text { Functionalized multi-walled carbon } \\
\text { nanotubes }\end{array}$ & $\mathrm{CNT}-\mathrm{OH}$ & $\begin{array}{l}\text { PU nanometric } \\
\text { modifier }\end{array}$ & $\begin{array}{c}\text { Nanostructured \& Amorphous } \\
\text { Materials, Inc., USA } \\
\text { Cat. no } 1249 \text { YJF }\end{array}$ & $\begin{array}{c}\text { Surface } \mathrm{OH} \text { groups } \\
1,67-1,85 \mathrm{wt} \% \\
\text { Purity }>95 \% \\
\text { Length } 0,5-2 \mu \mathrm{m} \\
\text { Outer diameter } 10 \text { - } \\
20 \mathrm{~nm} \\
\text { Inner diameter 5- } \\
10 \mathrm{~nm}\end{array}$ \\
\hline Carbon fibres & $\mathrm{CF}$ & PU modifier & $\begin{array}{c}\text { Carbon Pipreg }{ }^{\circledR} \text { Porcher Industries, } \\
\text { France } \\
\text { Cat. no } 3257-P 54\end{array}$ & $\begin{array}{c}\text { PU-based sizing agent } \\
\text { Diameter } \sim \mu \mathrm{m} \\
\text { Density }\left(\mathrm{g} / \mathrm{cm}^{3}\right): 1,5 \\
\text { Modulus }(\mathrm{GPa}): 235 \\
\text { Tensile strength }(\mathrm{MPa}): \\
4400\end{array}$ \\
\hline
\end{tabular}

decrease in the self-healing efficiency of the PU-based nanocomposites compared to neat PU [34]. During the selfhealing of damaged nanocomposites, nanotubes formed hydrogen bonds with PU chains, which resulted in an increase in the mechanical strength and thermal conductivity.

The purpose of this study was to synthesize self-healing $\mathrm{PU}$ as a matrix of nanocomposite samples with $\mathrm{CNT}-\mathrm{OH}$ and CF as modifying components and to assess the ability of such nanocomposites for self-healing. We have assumed that the presence of $\mathrm{CNF}-\mathrm{OH}$ and/or $\mathrm{CF}$, which have a clearly higher thermal conductivity compared to a neat polymer, will facilitate the transfer of heat from the environment to the interior of the nanocomposite sample necessary to repair the damaged site of a material. We used a selfhealing PU available on the market, which is used to fabricate self-healing coatings. In such coatings, the resulting surface defect self-heals as a result of ambient heat, e.g., solar heat. It can be expected that in such nanocomposites, slight damages arising under operating conditions, e.g., the fibre/matrix debonding, which may initiate material fracture, will selfheal.

\section{Materials and Methods}

2.1. Preparation of Material Components. The components listed in Table 1 were used for the synthesis of PU-based samples.

PTHF as polyol was chosen for its very good reactivity, chemical stability, ease of application, desired viscosity, and lower hygroscopicity as compared to poly(ethylene glycol).
The isocyanate is characterized by a high resistance to chemical environment, harsh weather conditions, and good mechanical properties. Before synthesis, both components, i.e., isocyanate and PTHF, were dried for 12 hours under the reduced pressure to 0,3 bar at $60^{\circ} \mathrm{C}$ and $100^{\circ} \mathrm{C}$, respectively. Functionalized multiwalled carbon nanotubes labelled as CNT-OH were used as the nanomodifier (nanocomponent), and carbon fibres labelled as (CF) were used as the second modifier of PU samples. To assure effective usage of CF in the PU matrix, before synthesizing the samples, the critical fraction and critical length of CF were calculated. The critical fibre fraction denotes the value above which the composite sample strength is higher than the strength of the pure matrix [35]. The calculated critical fraction of CF amounted to $0.072 \mathrm{v} \%(0,12 \mathrm{wt} \%)$, and the critical CF length was about $173 \mu \mathrm{m}$. Prior to use, continuous CF in the form of roving was cut into short fibres. The surface of these fibers was covered with a PU layer. For the synthesis of PU-based samples, we used CF with an average length of $3 \mathrm{~mm}$, that is, a length significantly exceeding the critical length, and with a greater $\mathrm{CF}$ content than the calculated critical fraction, i.e., $3 \mathrm{wt} \%$.

2.2. Preparation of Nanocomposite Samples. Figure 1 illustrates the procedure for the preparation of different PUbased samples.

Both carbon components, i.e., CNT-OH (nanomodifier) and CF (modifier), were introduced to the dried and melted PTHF and then homogenized by sonication. The sonication process of different CNT-OH/CF/PTHF compositions in the form of suspensions was conducted using a Cole Parmer $130 \mathrm{P}$ with $1 / 4$ " microtip. The amplitude was set at $80 \%$, which 


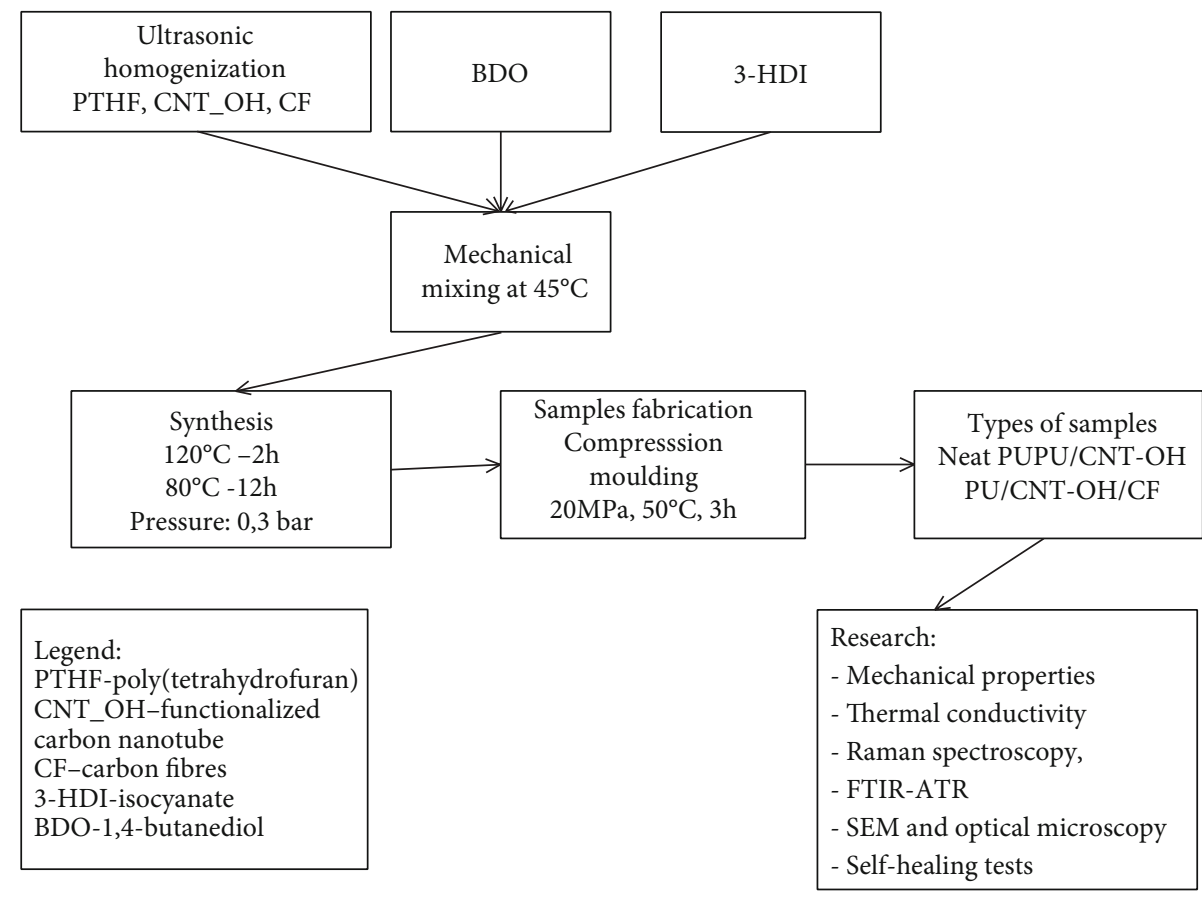

Figure 1: The block scheme of experimental procedure to prepare.

TABLE 2: Types of samples prepared for self-healing study and their names.

\begin{tabular}{lcccc}
\hline Isocyanate & Soft segment content (wt\%) & CNT-OH content (wt\%) & CF content (wt\%) & Name \\
\hline N3300 & 40 & 0 & 0 & PU40_CNT0_CF0 \\
N3300 & 40 & 2 & 3 & PU40_CNT2_CF0 \\
N3300 & 40 & 2 & 0 & PU40_CNT2_CF3 \\
N3300 & 50 & 0 & 0 & PU50_CNT0_CF0 \\
N3300 & 50 & 2 & 3 & PU50_CNT2_CF0 \\
N3300 & 50 & 2 & PU50_CNT2_CF3 \\
\hline
\end{tabular}

corresponded to about $14 \mathrm{~W}$ output power. During the sonication, the suspensions were kept at a constant temperature in a water bath.

To determine the optimal sonication time, a dynamic light scattering (DLS) method was used (ZetasizerNano-ZS, Malvern Instruments). The sonication lasted 2 minutes. First, the chain extender with catalyst was added at $55^{\circ} \mathrm{C}$, followed by adding the isocyanate. The whole composition was mechanically stirred and poured onto the mould consisting of two preheated Petri dishes $\left(70^{\circ} \mathrm{C}\right)$ and left for 2 hours at $105^{\circ} \mathrm{C}$. Then, the temperature was reduced to $80^{\circ} \mathrm{C}$ for another 10 hours. Then, the resulting PU/CNT-OH/CF composition in the form of sheets was placed between two steel plates and compressed under the pressure of $20 \mathrm{MPa}$ at $50^{\circ} \mathrm{C}$, for 3 hours. The synthesis conditions (heating temperature and cooling time) were determined based on the physical and chemical properties of the components. The amount of $\mathrm{CNT}-\mathrm{OH}$ in the polymer matrix was determined in our previous study [34]. It was shown that the amount of CNF$\mathrm{OH}$ above $2 \mathrm{wt} \%$ hinders the homogenization process and polymer synthesis. For this reason, nanocomposites containing $1 \mathrm{wt} \%$ and $2 \mathrm{wt} \%$ were prepared for the experiments.
The types of samples and their labelling for further experiments are given in Table 2.

Two types of neat PU-based samples, differing in the content of soft and stiff segments and two types of nanocomposites were synthesized, namely, nanocomposites containing only CNT-OH (1 and 2\%) and nanocomposites containing $\mathrm{CNT}-\mathrm{OH}$ and $3 \% \mathrm{CF}$.

The contents of PU synthesis components, i.e., the amount of functional groups derived from isocyanates and hydroxyl groups derived from polyol and chain extender, were calculated from the formula taking into account their reactivity and equilibrium conditions of the polymerization reaction. The stoichiometric PU compositions assuming $40 \%$ and $50 \%$ of soft segments were prepared. The polyurethane blend was selected based on its mechanical strength. The following PU-CNT-OH nanocomposite has been prepared: the $10 \mathrm{~g}$ PU composition with $40 \%$ of soft segments consisted of $5.19 \mathrm{~g}$ isocyanate, $4 \mathrm{~g}$ polyol, $0.81 \mathrm{~g}$ chain extender, CNT-OH (various amount), and CF $3 \mathrm{wt} \%$. The $10 \mathrm{~g}$ PU composition with $50 \%$ of flexible segments consisted of $4.45 \mathrm{~g}$ isocyanate, $5 \mathrm{~g}$ polyol, $0.55 \mathrm{~g}$ chain extender, CNT$\mathrm{OH}$ (1 and $2 \mathrm{wt} \%$ ), and CF $3 \mathrm{wt} \%$ (details in [34]). 


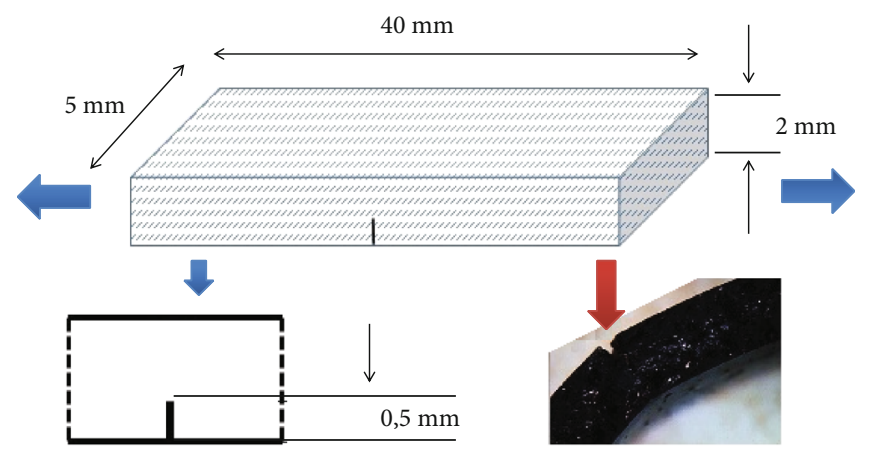

FIgURE 2: Geometry of sample with controlled incision for tensile tests; microphotograph shows the incision in the bent sample.

2.3. Methods. To assess the self-healing properties of neat polymers and composite/nanocomposite materials, various techniques in the literature can be found [25]. So far, standard tests to examine self-healing effects in the materials have not been developed. In our experiments, the effect of selfhealing in nanocomposites was determined by comparing the mechanical strength of the as-received (initial) samples and experimentally damaged samples before and after the healing process. The damaged samples contained an incision imitating damage in samples with strictly defined geometry ( $5 \mathrm{~mm}$ width and $0.5 \mathrm{~mm}$ depth) were made using a microtom EXTEC Labcut 150 (Figure 2).

The ratio of the tensile strength of the damaged sample after self-healing to the strength of the initial sample was considered as the healing level in a percentage.

For these tests, two types of samples were prepared:

(1) reference samples, whose strength values were used as the initial values

(2) damaged samples containing incision for healing tests

Then, the damaged samples were heated at $60^{\circ} \mathrm{C}$, for 3 hours (self-healing phase), and subsequently, four of them were tested to determine their mechanical properties after the first cutting/healing $(\mathrm{C} / \mathrm{H})$ cycle. After the first cycle, the remaining samples were incised again to create damage, and the heating process was repeated. For neat PU-based samples and modified with $\mathrm{CNT}-\mathrm{OH}$, the $\mathrm{C} / \mathrm{H}$ cycles were repeated five times, whereas for nanocomposites containing both carbon components, the $\mathrm{C} / \mathrm{H}$ cycles were repeated three times. After each $\mathrm{C} / \mathrm{H}$ cycle, the samples were subjected to mechanical testing. The temperature and time of the healing process were determined experimentally.

Fourier Transform Infrared spectroscopy (ATR-FT-IR) was performed using a Bio-Rad FTS 165 spectrometer with a resolution of $2 \mathrm{~cm}^{-1}$ (64 scans). Spectra were recorded in the range of $4000-400 \mathrm{~cm}^{1}$. Raman spectroscopy was performed using a HORIBA LabRAM HR spectrometer. The measurements were carried out with a laser excitation wavelength of $532 \mathrm{~nm}$.

The coefficient of thermal conductivity (CTC) was determined using the cut-bar comparative method in steady-state thermal conditions according to ASTM E1225-87 standard using a laboratory test apparatus designed for measuring composite and nanocomposite samples. The static mechanical properties (strength, tensile modulus, and work of fracture) of samples (PU40_CNT0_CF0, PU50_CNT0_CF and nanocomposites) were determined in tensile uniaxial tests on an universal testing machine Zwick (model 1435) PC controlled by TestXpert (v.8.1) software, with the strain rate of 2 $(\mathrm{mm} / \mathrm{min})$. Laboratory internal tests were performed using rectangular samples of the size $40 \mathrm{~mm} \times 5 \mathrm{~mm} \times 2 \mathrm{~mm}$ cut from a synthesized PU-based sheet. The samples were mounted in grips of the testing machine, $24 \mathrm{~mm}$ apart (gauge length). The grips were covered with a silicon layer to avoid damaging the surface of the samples during the tensile test. The tensile modulus of the samples was determined from the slope of the straight line of the stress-strain relationship.

The total work of fracture values of samples was determined based on the measurements of the surface areas under the force-strain-curves obtained at a constant rate of stretching up to fracture. Mechanical parameters of the initial samples (undamaged samples) were obtained as the mean \pm standard deviation of five measurements, while four measurements were made for samples used in self-healing tests. Differences in mechanical strength and self-healing capability among samples $(n=4)$ were tested with Student's $t$-test with a significance level of $p<0.05$.

\section{Results}

3.1. Mechanical Properties. Changes in the mechanical properties of the nanocomposites (tensile strength and tensile modulus) modified with CNT-OH are shown in Figure 3.

As is apparent from these plots, the addition of CNT-OH up to $2 \mathrm{wt} \%$ significantly affects the mechanical properties of the resulting nanocomposites. In particular, a significant increase in the tensile modulus was observed.

Figure 4 illustrates changes in the strength and tensile modulus of PU-based nanocomposite samples in the presence of both carbon components.

The starting points of both plots (Figure 4(a)) correspond to samples made of neat $\mathrm{PU}$, and the remaining ones contain $3 \% \mathrm{CF}$ addition and $1 \%$ and $2 \% \mathrm{CNT}-\mathrm{OH}$, respectively.

The nanocomposites containing both carbon components are characterized by a significantly higher strength and tensile modulus compared to nanocomposites containing only CNT-OH (Figure 3). 


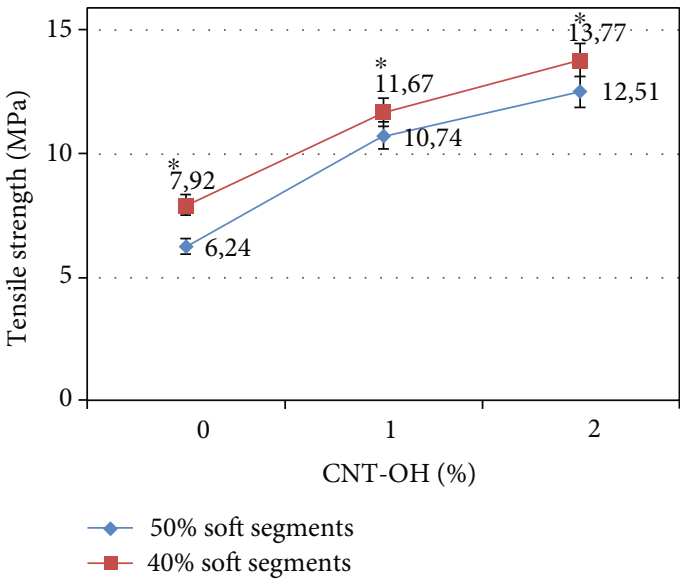

(a)

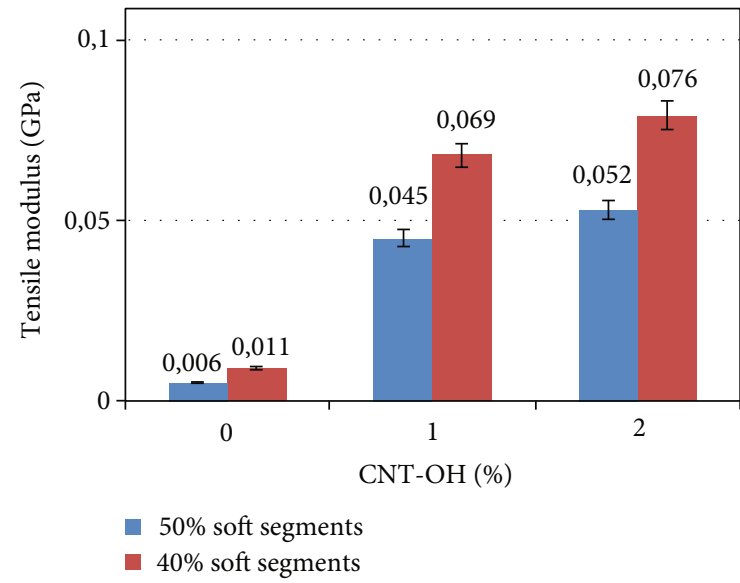

(b)

FIGURE 3: Tensile strength (a) and tensile modulus (b) of samples in function of CNT-OH content $\left({ }^{*}\right)$ denotes statistically significant difference between the samples differing in the content of soft segments $(p<0.05)$.

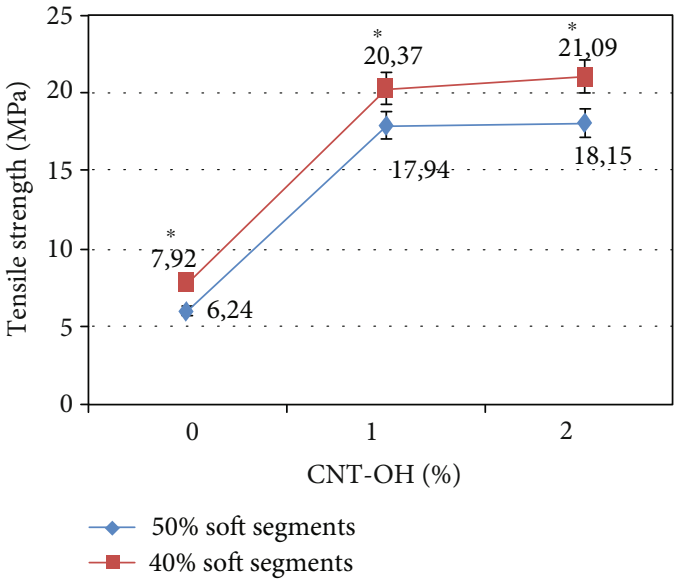

(a)

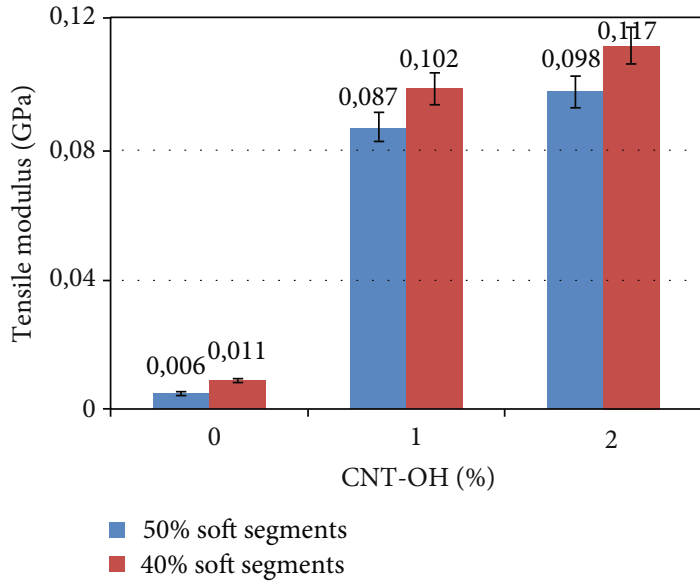

(b)

FIgURE 4: Tensile strength (a) and tensile modulus (b) of neat PU and modified with CF in function of CNT-OH content * denotes statistically significant difference between the samples differing in the content of soft segments $(p<0.05)$.

The comparison of the mechanical properties of PU samples containing up to $2 \mathrm{wt} \%$ of $\mathrm{CNT}-\mathrm{OH}$ with the samples containing both carbon phases indicates that $\mathrm{CF}$ strengthens the PU matrix more effectively than CNT-OH. In the case of samples with $\mathrm{CNT}-\mathrm{OH}$, the improvement in the tensile strength does not exceed several dozen percent, while in the case of PU with $3 \%$ content of CF the increase in the tensile strength is almost $300 \%$. The difference in mechanical properties between samples containing $1 \%$ and $2 \% \mathrm{CNF}-\mathrm{OH}$ is relatively low. The effect of $\mathrm{CF}$ is even more pronounced for the modulus of elasticity. For PU40_CNT2_CF3 samples, the modulus increases by almost $2000 \%$, whereas for the PU50_CNT2_CF3 samples, by $1100 \%$, as compared to neat PU samples (Figure 3).

Such a significant increase in the mechanical parameters of samples modified with carbon components may prove that they are uniformly dispersed in the PU matrix, and both components behave as a reinforcing phase. The full dispersion of CNT and their uniform distribution in a polymer matrix are an important prerequisite factor, necessary for the improvement of mechanical parameters of resulting nanocomposites. Another factor is the matrix-CNT/CF interfacial bonding that ensures effective load transfer from the PU to carbon fibrous components $[34,36]$. This is also confirmed by the low standard deviations of the means values of the mechanical strength and tensile modulus (below $2 \%$ ).

3.2. Thermal Conductivity. The thermal conductivities of nanocomposites modified with CNT-OH $(1 \%, 2 \%)$ and CF (3\%) are shown in Figure 5.

As is apparent from this figure, the addition of $\mathrm{CNT}-\mathrm{OH}$ and CF improves the CTC of samples. The increase in CTC of CNT-OH modified samples is about $40 \%$, while for samples containing both carbon components, about $140 \%$, compared to neat PU. Moreover, CF affects much stronger on CTC growth of nanocomposites compared to CNT-OH. These results also confirm the conclusions drawn from mechanical tests regarding good dispersion and uniform 


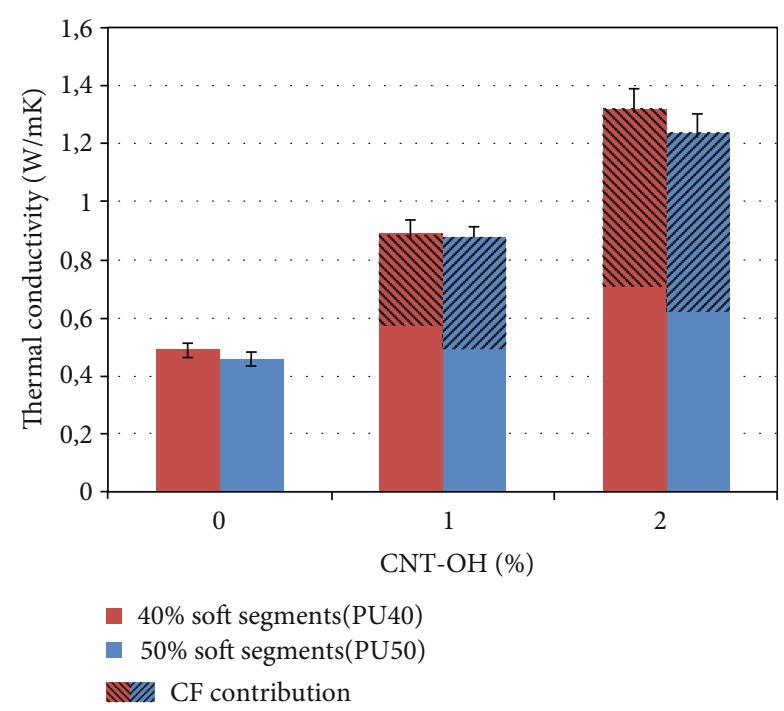

FIGURE 5: Thermal conductivity of neat PU and modified with $\mathrm{CNT}-\mathrm{OH}$ and $\mathrm{CF}$.

distribution of both carbon modifiers in the PU matrix. The improvement of heat transport in the polymer matrix modified with the electrically conductive phase (carbon) requires exceeding the percolation threshold of carbon components or creating a strong bond of the polymer to the carbon surface [37-39]. The percolation threshold corresponds to the critical content at which the conductive path throughout the entire sample occurs. In the first case, the conduction mechanism is similar to the electron mechanism in metals (a contribution of quasi-free electron) [37-41]. However, the PU-based nanocomposites were not electrically conductible; therefore, the percolation threshold was not achieved (data not published). A strong interaction at the interphase between the polymer structure and the functional surface groups of the fibrous components may promote heat conduction by means of the phonon-phonon mechanism. Therefore, it is likely that in the nanocomposite structure, the significant increase in thermal conduction is caused by interfacial bonding formed between the PU matrix and the CNT and CF. It cannot be also excluded that the fibrous carbon components crosslink PU chains to form transverse bonds.

3.3. ATR-FT-IR and Raman Spectroscopy. The interaction between characteristic groups of neat PU and nanocomposite samples can be identified by analysis of the shifts in absorption frequencies of selected bands of the polymer and carbon components after synthesis. Figure 6 shows the FTIR spectra of neat PU and nanocomposites containing $\mathrm{CNT}-\mathrm{OH}$ and CF. Additionally, the spectra of carbon components are shown.

The spectrum of neat PU contains two characteristic bands at $2859 \mathrm{~cm}^{-1}$ and $2940 \mathrm{~cm}^{-1}$ attributed to symmetric and asymmetric stretching vibrations of $\mathrm{CH}_{2}$ groups. The band at $1100 \mathrm{~cm}^{-1}$ of neat PU is assigned to the asymmetric stretching vibration of C-O-C groups. These bands, characteristic for the polymer matrix, are depicted in the spectra by the marking lines. The spectra of nanocomposite samples containing both carbon components show distinct wavenumber shifts to higher wavenumbers of the bands originating from C-H stretching vibrations at $2940 \mathrm{~cm}^{-1}$ and $2859 \mathrm{~cm}^{-1}$ compared to the neat PU. A similar shift is observed for stretching of C-O-C groups, from $1100 \mathrm{~cm}^{-1}$ for neat PU to $1138 \mathrm{~cm}^{-1}$ for nanocomposite samples. This may indicate that the carbon components interact with the polymer matrix. Functionalized CNT-OH surface contains $\mathrm{OH}, \mathrm{C}=\mathrm{O}$, and $\mathrm{C}-\mathrm{C}-\mathrm{O}$ groups [34]. However, carbon materials are electrically conductive, and due to electron absorption, bands derived from surface chemical groups in the CNT and CF spectra are invisible. Only the broad and weak band in the range of $3200-3500 \mathrm{~cm}^{-1}$ corresponding to the $\mathrm{C}-\mathrm{OH}$ groups in the $\mathrm{CNT}$ can be observed. Nanometric $\mathrm{CNT}-\mathrm{OH}$ dispersed and distributed in a polymer matrix is not visible in the FTIR spectrum as a separate phase [42-44].

Absorption band at $1718 \mathrm{~cm}^{-1}$ is characteristic for hydrogen-bonded carbonyl group in urethanes at the interface between hard and soft segments, whereas the band at $1682 \mathrm{~cm}^{-1}$ can be brought about by the hydrogen-bonded carbonyl group in urethane hard segments [45]. In the FTIR spectra of nanocomposites, both these bands are shifted towards higher wavenumbers (the shifts of the bands are marked with lines), which can indicate that carbonyl groups are involved in the creation of new hydrogen bonds. The lack of absorption bands of hydroxyl groups in the spectra of PU modified with CNT-OH and CF may also indicate the chemical interaction between functionalized carbon surface and isocyanates. The analysis of these spectra clearly shows the impact of the fibrous carbon phases on the PU structure and may indicate chemical interaction with the PU matrix. This analysis also suggests that carbon components are uniformly dispersed in a polymer matrix, without creating greater particles in the form of separated phases (agglomerates). The spectra of PU do not contain bands from unreacted isocyanate and hydroxyl groups, while bands from urethane groups are visible. This indicates that the isocyanate groups derived from the isocyanate and the hydroxyl groups derived from the chain extender and polyol had completely reacted with each other to form polyurethane.

The Raman spectra of the different samples, including carbon components as separate CNT-OH and CF spectra, are shown in Figure 7.

Raman spectroscopy can be a useful tool for monitoring the manufacturing process and modification of various nanocomposites, e.g., CNT. Specific band shifts in the Raman spectrum may indicate a possible interaction between CNT and PU matrix, the level of CNT dispersion of the nanocomponents in the matrix, as well as stresses that may arise during nanocomposites processing [46-49].

Peaks related to $\mathrm{CNT}-\mathrm{OH}$ and $\mathrm{CF}$ spectra are shown by the marking lines. In the CNT-OH spectrum, the characteristic peaks at $1359 \mathrm{~cm}^{-1}$ (D band) and $1650 \mathrm{~cm}^{-1}$ ( $\mathrm{G}$ band) are clearly observed, whereas in the CF spectrum, these peaks are localized at $1353 \mathrm{~cm}^{-1}$ and $1663 \mathrm{~cm}^{-1}$, respectively. The D peak corresponds to the fraction of the disordered carbon phase in carbon components, and the $\mathrm{G}$ band is related with the fraction of the ordered graphitic phase. The spectra of $\mathrm{CF}$ and CNT-OH also contain overtone of the D' mode observed 


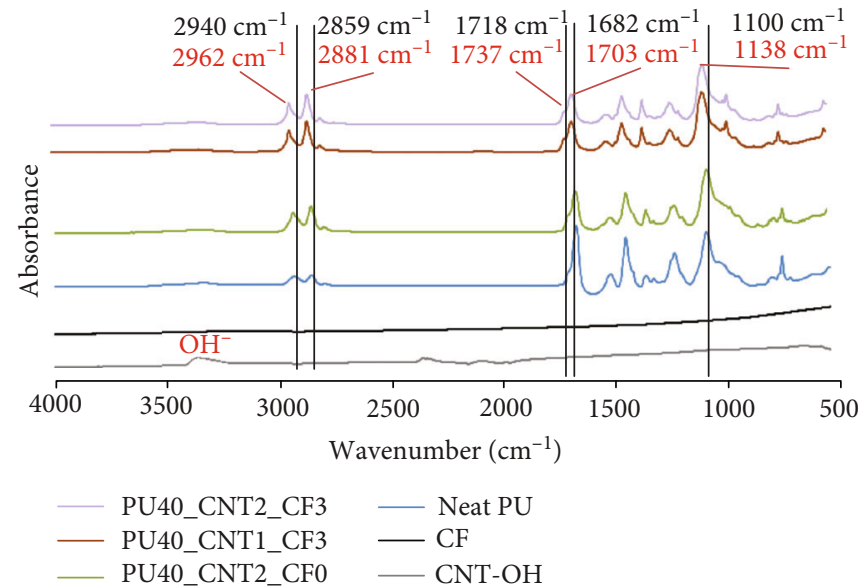

FIGURE 6: FTIR spectra of neat PU, carbon components, and nanocomposites modified with CNT-OH and CF.

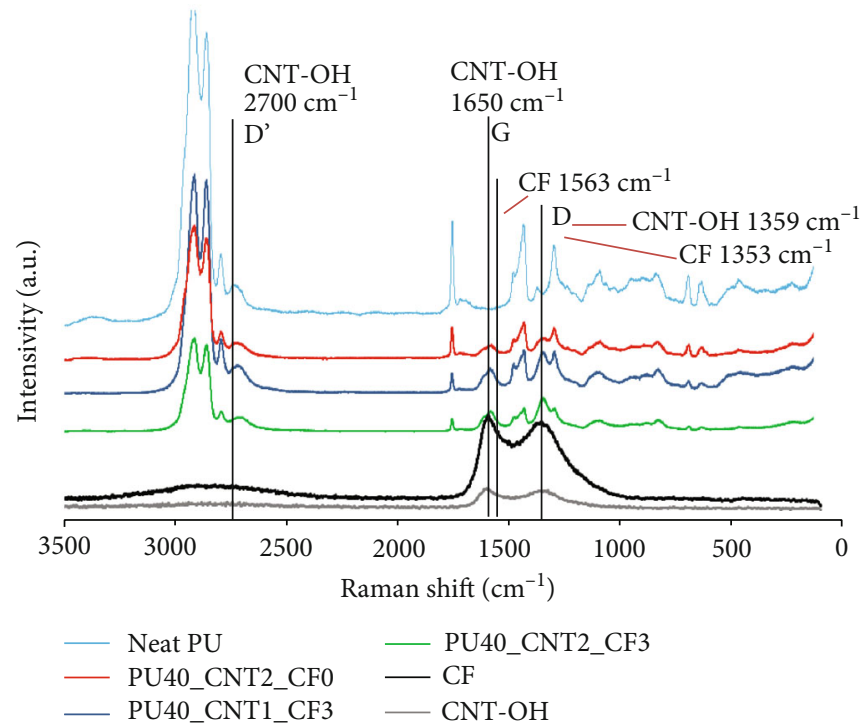

FiguRE 7: Raman spectra of neat PU, carbon components, and nanocomposites.

at about $2700 \mathrm{~cm}^{1}$. The spectra indicate that both carbon components have a similar structure. The structure of $\mathrm{CF}$ has already been the subject of our previous study [50].

The examination of the Raman spectra of nanocomposite samples showed neither significant shifts of the peaks associated with the PU matrix nor shifts of the D and G peaks derived from carbon components. However, the presence of carbon components causes a clear reduction in the intensity of the PU-characteristic bands, which may indicate the uniform distribution of both carbon phases in the polymer matrix.

3.4. Self-Healing Ability of the Nanocomposites. Figure 8 shows changes in the tensile strength of samples obtained from neat.

$\mathrm{PU}$ and nanocomposites containing incision (damaged samples) after thermal activation in the subsequent $\mathrm{C} / \mathrm{H}$ cycle.

The nanocomposites PU40_CNT2_CF3 have a higher tensile strength $(21.09 \mathrm{MPa})$ compared to PU50_CNT2_
CF3 (18.15 MPa). After the first $\mathrm{C} / \mathrm{H}$ cycle, the samples recover about $72 \%$ of their initial strength. In the subsequent cycle, changes in strength are no longer statistically significant $(p<0.05)$. In all examined samples after healing, the strengths are higher than those observed for the damaged samples. Figure 9 compares the self-healing level of samples differing in the content of soft segments.

As can be seen from this figure, the highest healing level was recorded for the samples PU40_CNT2_CF3, and this level is about 6\% higher as compared to PU50_CNT2_CF3. The presence of $\mathrm{CF}$ in the polymer matrix reduces the susceptibility of the nanocomposites to healing compared to neat PU. However, a detailed analysis of the increase in strength of the damaged samples after successive $\mathrm{C} / \mathrm{H}$ cycles indicates that for nanocomposites, this increase (strength recovery) is higher than that observed for neat PU. Table 3 summarizes the healing effects of neat $\mathrm{PU}$ and nanocomposites after successive $\mathrm{C} / \mathrm{H}$ cycles. 


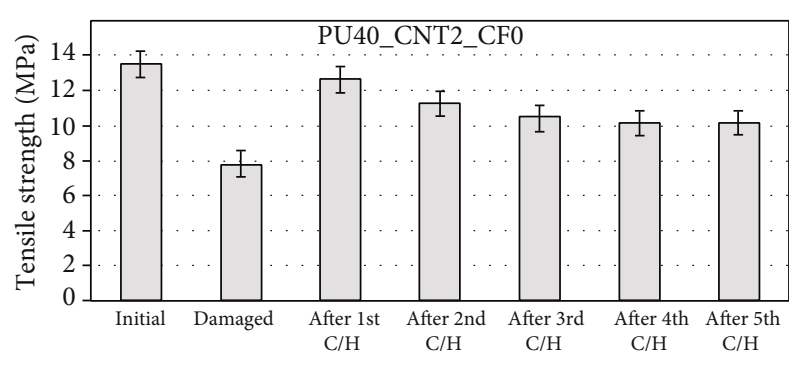

(a)

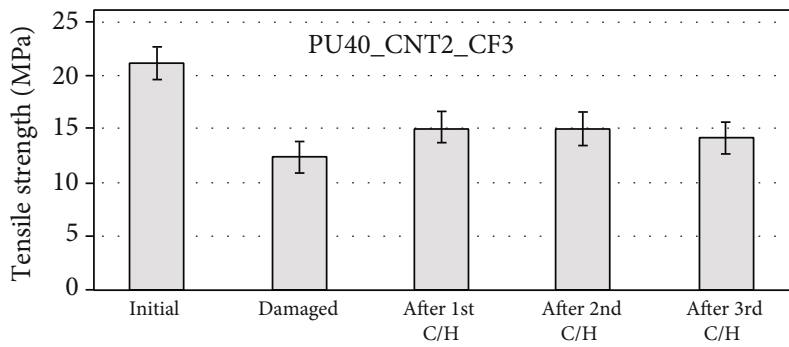

(c)

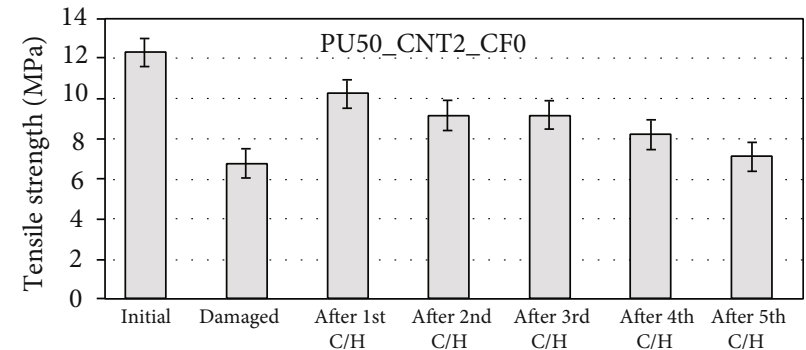

(b)

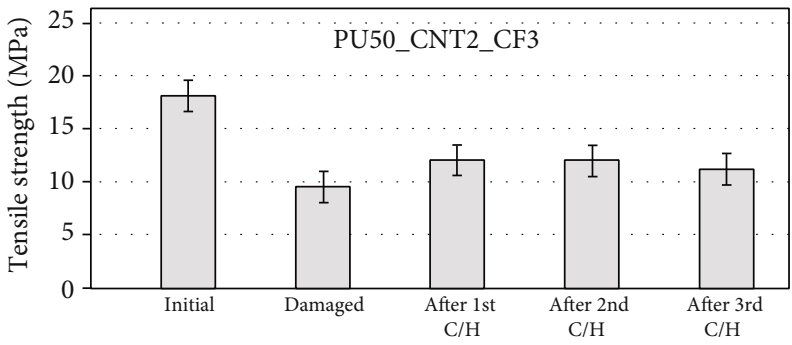

(d)

FIgURE 8: Changes in tensile strength of nanocomposites in the function of the number of $\mathrm{C} / \mathrm{H}$ cycles.

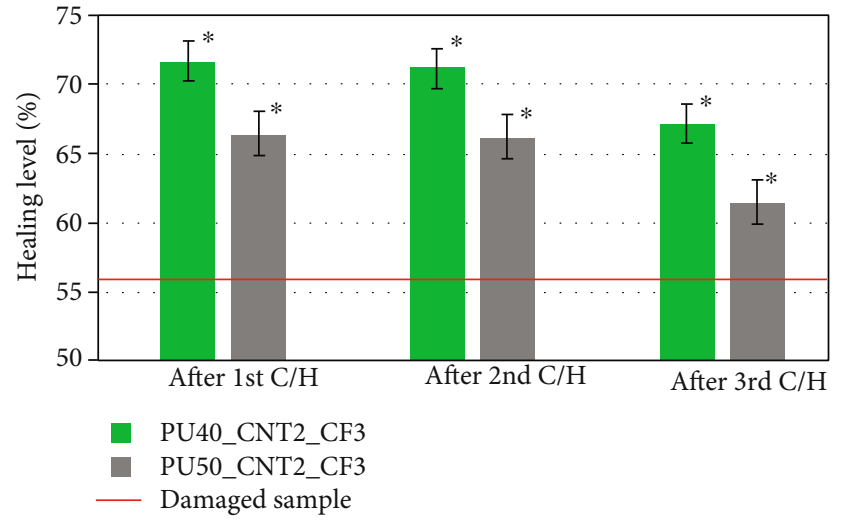

FIGURE 9: Comparison of the healing level of nanocomposites after the first $\mathrm{C} / \mathrm{H}$ cycles $\left({ }^{*}\right)$ denotes a statistically significant difference between damaged samples and after healing $(p<0.05)$.

The table compares the healing levels (in percents) and increase in strength after subsequent $\mathrm{C} / \mathrm{H}$ cycles for neat $\mathrm{PU}$ and nanocomposites. The highest healing level was obtained for neat PU-based samples, and damaged samples regained $98,3 \%$, and $96.5 \%$ of the initial strength after the first $\mathrm{C} / \mathrm{H}$ cycle, respectively. This can be attributed to the high mobility of polymer chains and the lack of barriers inhibiting their migration in the neat PU during thermal activation of the damaged structure. The lowest healing level, i.e., $60-70 \%$ of the initial tensile strength, was found for nanocomposites modified with both carbon phases. It should be noted, however, that the initial tensile strength of these nanocomposites is three times greater than the strength of neat PU. Comparison of the strength gain after the first $\mathrm{C} / \mathrm{H}$ cycle of damaged neat PU samples (2.54 MPa) with nanocomposite modified with CNT-OH and $\mathrm{CF}(2.76 \mathrm{MPa})$ suggests that the self-healing may also occur at the interphases in samples, i.e., between the surface of the detached fibre and the matrix (Table 3).

\section{Discussion}

The study showed that from the two types of PU-based matrices differing in the content of soft segments, the polymer containing a lower content of these segments was characterized by more favorable mechanical parameters and higher CTC. Such a relationship was also observed in the case of the CNT-OH modified polymer. However, the introduction of carbon components clearly reduced the effect of the neat polymer structure on the mechanical properties (Figure 3) and thermal conductivity (Figure 5) of the nanocomposites. The differences in mechanical parameters and CTC of nanocomposites modified with both carbon components were not statistically significant, regardless of the content of soft segments.

The introduction of a damage to a nanocomposite in the form of a deep incision (1/4 the thickness of the sample), across its entire width, significantly reduces its effective cross-section. Usually, such large defects do not occur in materials under service loading conditions. In nanocomposites containing low contents of $\mathrm{CF}$ and carbon nanotubes, sample fracture can occur either by fibrous components pulling out from polymer matrix or by debonding fibre-matrix interphase. $\mathrm{CF}$ or $\mathrm{CNT}-\mathrm{OH}$ fracture during stretching test in such samples is rather unlikely. This is due to the fact that carbon nanotubes and CF are very short and strong. Failure of carbon fibrous component can happen only in composites/nanocomposites reinforced with continuous microfibres with a strong interfacial boundary between the matrix and the fibre surface. The healing process of the damage in our nanocomposites can be described taking into consideration 
TABLE 3: Comparison of healing effects of different samples and increases in strengths of damaged samples after $\mathrm{C} / \mathrm{H}$ cycles.

\begin{tabular}{lccccc}
\hline Name/type of sample & $\begin{array}{c}\text { Healing after } \\
\text { I C/H cycle (\%) }\end{array}$ & $\begin{array}{c}\text { Healing after } \\
\text { II C/H cycle (\%) }\end{array}$ & $\begin{array}{c}\text { Healing after } \\
\text { III C/H cycle (\%) }\end{array}$ & \multicolumn{3}{c}{ Increase in strength (MPa) } \\
After I C/H & After II C/H & After III C/H \\
\hline PU40_CNT0_CF0 & 98,3 & 95,6 & 92,5 & 2,54 & 2,33 \\
PU40_CNT2_CF0 & 93,3 & 83,4 & 77,2 & 4,80 & 3,46 \\
PU40_CNT2_CF3 & 71,7 & 71,2 & 67,2 & 2,76 & 2,64 \\
PU50_CNT0_CF0 & 96,5 & 92,5 & 93,3 & 2,34 & 2,31 \\
PU50_CNT2_CF0 & 83,3 & 74,5 & 74,6 & 3,94 & 2,87 \\
PU50_CNT2_CF3 & 66,5 & 66,2 & 61,5 & 2,54 & 2,45 \\
\hline
\end{tabular}

two probable mechanisms, i.e., by restoring broken hydrogen bonds between urethane groups of PU chains and/or by reaction between functional chemical groups present on the surface of both carbon components and urethane groups of the PU matrix. The first mechanism, known from the literature, describes the regeneration of a damaged site in PU used in this work.

Figure 10 illustrates a model of the nanocomposite sample containing $\mathrm{CNT}-\mathrm{OH}$ and $\mathrm{CF}$ and the probable mechanism of chemical and hydrogen bonding between the selfhealing PU and carbon components.

Damage caused by breaking the hydrogen bonds between the polymer chains in neat PU is repaired by absorbing heat from the environment. The broken hydrogen bonds during this process are rebuilt. In nanocomposites, during PU synthesis, chemical bonds can be formed between the surface of carbon components and PU. Such bonds may be formed only when functionalized CNT-OH and CF are added to PU matrix prior to the synthesis. This is the advantage of the method used in this work for the fabrication of nanocomposites, as opposed to direct mechanical mixing of polyurethane in granules with carbon components, ensuring only physical binding to the matrix. Figure 11 shows the surface images of PU40_ CNT2_CF_0 before and after the self-healing process.

The SEM microphotographs in Figure 11(a) and (b) show the damaged surface of the sample before healing. After heating the samples $\left(60^{\circ} \mathrm{C}, 30 \mathrm{~min}\right)$, the damaged sites shown on the surface (b) disappeared. However, some sites with a not fully rebuilt surface can also be noticed. Figures 11(c) and 11(d) presents the SEM microphotographs of the sample surface with the white line marking the initially made incision after complete regeneration. The incision marked with the line is clearly visible. On the samples' surface, elongated damages parallel to the direction of the incisions remained after healing can also be seen. The SEM images reveal the selfhealing during the thermal treatment of the damaged sample.

The influence of carbon components in the healing process of nanocomposites can also be considered by analysing the total work required to fracture a sample in the tensile test. The tensile force-strain plots for damage-free samples, damaged, and self-healed samples are shown in Figure 12.

During the tensile test, the force-strain function shows two different ranges: initially, the function is straight-linear, whereas above $4 \%$, the strain increments are much greater, which is associated with sample plastic deformation, due to the breaking of cross-linking bonds in the polymer containing $\mathrm{CNT}-\mathrm{OH}$ and $\mathrm{CF}$. The nanocomposites subjected to the $\mathrm{C} / \mathrm{H}$ cycle are characterized by a decrease in the plastic deformation range before reaching the maximum of fracture force compared to the as-received nanocomposites without incision. The fracture of these samples during stretching occurs at lower absolute strains and at lower fracture force, compared to the as-received nanocomposite. By comparing the surface areas under the curves that represent the total fracture work, it can be seen that the healed PU_CNT2_ $\mathrm{CF} 3$ displays distinctly reduced surface areas compared to the values determined for undamaged samples. In these samples, the damage caused a decrease in their mechanical parameters, whereas the regeneration process activated by heating led to partial restoration of the matrix structure and the matrix/CF interphase. The marked areas under the curves (Figure 12) represent increments in the fracture work of damaged nanocomposites after the self-healing process. The values of fracture work characterizing three types of samples, i.e., neat PU and both nanocomposites before and after selfhealing are collected in Table 4.

The last column in Table 4 shows the strain to failure of three types of damage-free samples (before damaging). These values are noticeably reduced for $\mathrm{CNT}-\mathrm{OH}$ and $\mathrm{CF}$-modified nanocomposites.

Nanocomposites containing CNT-OH and CF, after the first $(\mathrm{C} / \mathrm{H})$ cycle, are characterized by a lower level of fracture work (about 39\% compared to the undamaged nanocomposite) than neat PU (about 86\%, compared to undamaged PU); the total work required to fracture these nanocomposites is distinctly higher. The total fracture work $\left(W_{T}\right)$ absorbed during the tensile test of the nanocomposites containing both carbon components can be written as follows:

$$
W_{T}=\mathrm{W}_{\mathrm{PU}}+\mathrm{W}_{\mathrm{CF}}+\mathrm{W}_{\mathrm{CNT}-\mathrm{OH}},
$$

where $W_{T}$ is the total fracture work. $W_{\mathrm{PU}}$ the fracture work of neat PU matrix; $W_{\mathrm{CF}}$ and $W_{\mathrm{CNT}-\mathrm{OH}}$ are the fracture work components referred to the presence of $\mathrm{CF} /$ matrix and $\mathrm{CNF}$ $\mathrm{OH} /$ matrix interphases.

The equation represents the contribution of three components of the nanocomposite, i.e., PU, CNT-OH, and CF into the total work required to fracture the sample. As can be seen from Table 4, the introduction of CNT-OH to the PU matrix increases the recovered fracture work after first healing from $49.9 \mathrm{~J} / \mathrm{mm}^{2}$ (neat PU) to $73.2 \mathrm{~J} / \mathrm{mm}^{2}$. In nanocomposite samples with both carbon components, the fracture work recovered after the healing increased up to $85 \mathrm{~J} / \mathrm{mm}^{2}$. The above considerations indicate that the healing process may take place 


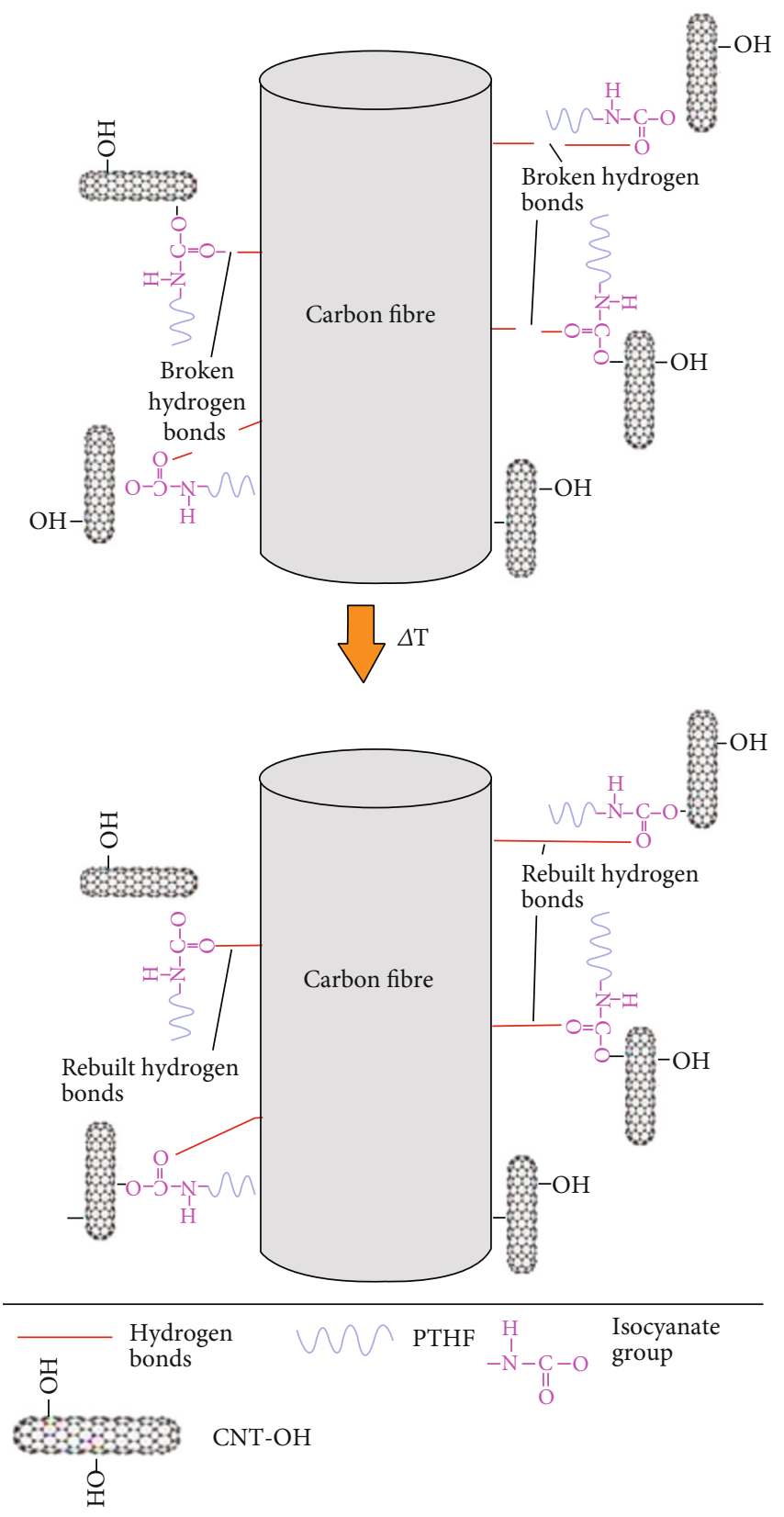

FIgure 10: Scheme of healing mechanism in the PU matrix containing CNT-OH and CF.

not only in the damaged polymer matrix, but also between the detached $\mathrm{CF}$ and/or CNT-OH from the PU matrix.

The conducted experiments indicate the possibility of extending the use of self-healing polymers in the form of nanocomposite coatings with improved mechanical properties and better thermal conductivity compared to unmodified PUbased coatings, while maintaining its self-healing properties. The role of carbon phases in the polymer matrix is not limited to improving the mechanical parameters of the nanocomposite and formation of additional interphase boundaries involved in the self-healing process. Carbon components increase the thermal conductivity of the nanocomposite, thanks to which the heat transport from the environment to the interior of the sample, necessary to initiate the self-healing process, is more effec- tive. This fact may be important in the case of the synthesis of nanocomposite materials with a thickness exceeding the thickness of typical PU coatings. The results of our study showed that self-healing can occur in samples with a thickness of $2 \mathrm{~mm}$. However, it cannot be ruled out that due to the presence of carbon components with a high thermal conductivity in the polymer material, this process will also take place in materials with larger transverse sizes.

In structural composites, containing continuous fibres as reinforcement, e.g., carbon fibres, fracture mechanism is initiated as a result of the formation of microcracks of very small sizes (subtle cracks) by debonding of fibre-matrix interphases [51]. Such damages initiating the fracture process in composites can be formed under service loading conditions. 

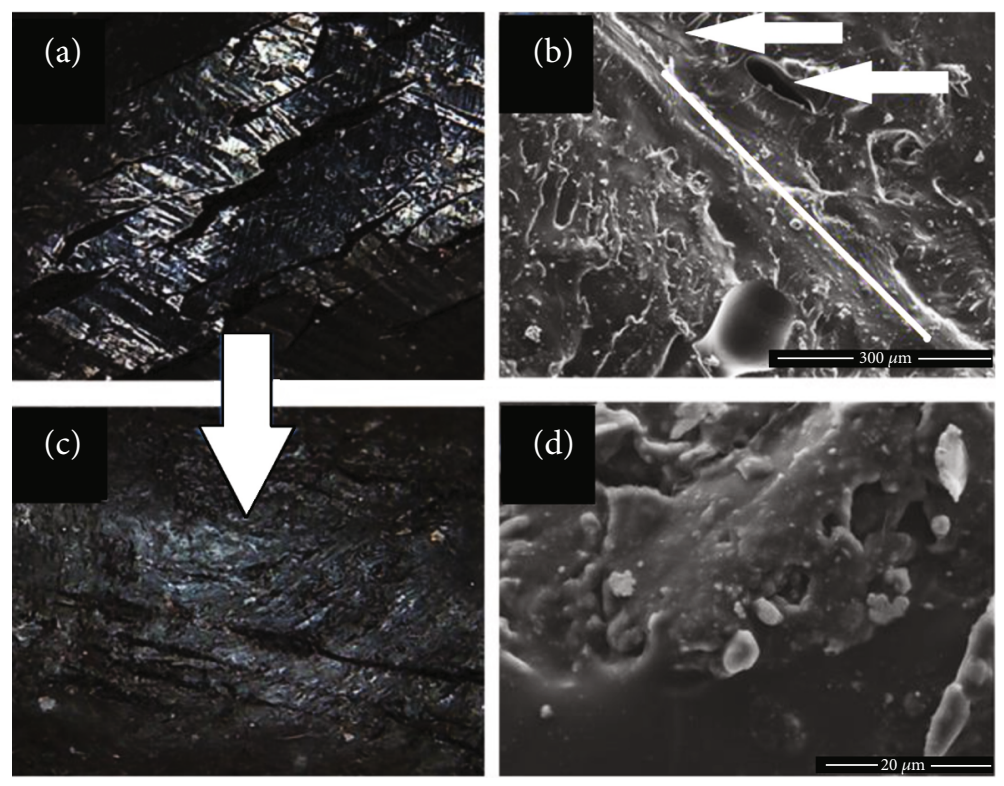

FIGURE 11: SEM images of nanocomposite surfaces before $(a, b)$ and after $(c, d)$ self-healing; self-healed surface sites are marked with a white line and arrows.

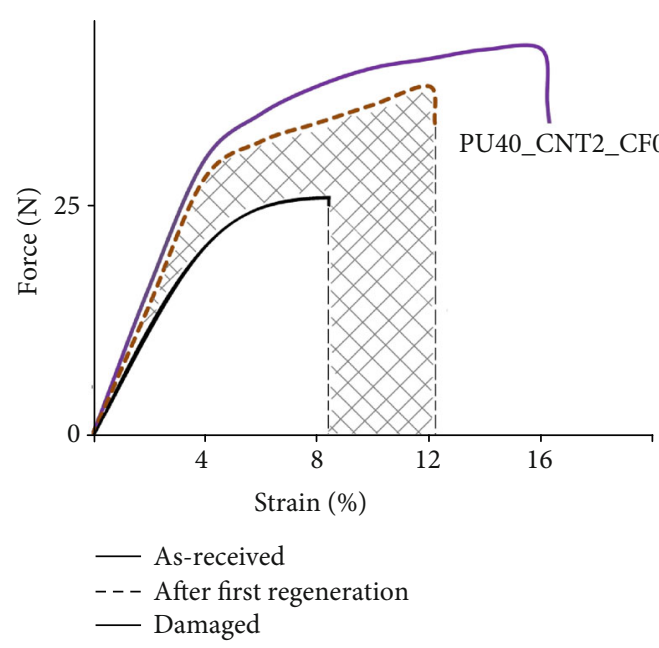

(a)

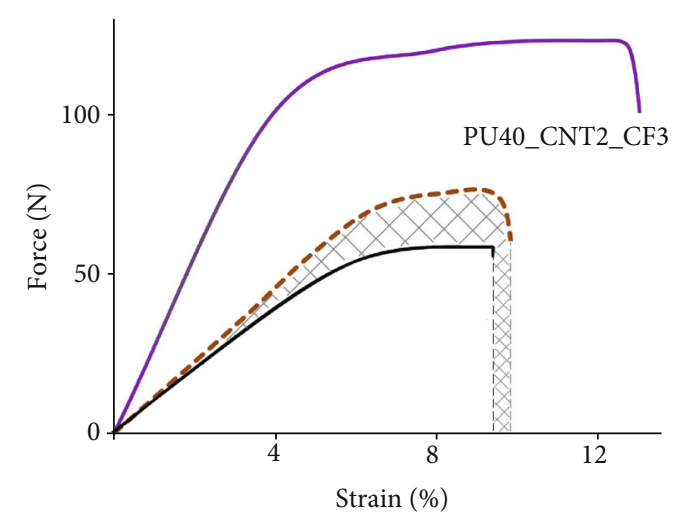

(b)

FIGURE 12: Force-strain plots of the nanocomposites before and after self-healing; (a) PU modified with CNT-OH, (b) PU modified with $\mathrm{CNT}-\mathrm{OH}$ and CF.

TABLE 4: Comparison of fracture works of undamaged, damaged, and healed samples under tensile tests.

\begin{tabular}{|c|c|c|c|c|c|}
\hline Type of sample & $\begin{array}{c}\text { Fracture work of } \\
\text { undamaged samples }(\mathrm{N} \cdot \mathrm{mm})\end{array}$ & $\begin{array}{l}\text { Fracture work of damaged } \\
\text { samples }(\mathrm{N} \cdot \mathrm{mm})\end{array}$ & $\begin{array}{c}\text { Fracture work after } 1^{\text {st }} \\
\mathrm{C} / \mathrm{H} \text { cycle }(\mathrm{N} \cdot \mathrm{mm})\end{array}$ & $\begin{array}{l}\text { Recovered fracture } \\
\text { work }\left(\mathrm{J} / \mathrm{mm}^{2}\right)\end{array}$ & $\begin{array}{c}\text { Strain to } \\
\text { fracture (\%) }\end{array}$ \\
\hline PU40_CNT0_CF0 & 131.5 & 62.8 & 112.7 & 49.9 & 18.1 \\
\hline PU40_CNT2_CF0 & 270.2 & 101.4 & 174.6 & 73.2 & 16.2 \\
\hline PU40_CNT2_CF3 & 652.2 & 161.4 & 246.4 & 85.0 & 12.5 \\
\hline
\end{tabular}

The use of self-healing PU as a matrix of structural composites can contribute to enhance their durability (life-time), due to the possibility of healing damages that are formed at the early stage of fracture. However, this suggestion requires experimental verification.

\section{Conclusions}

The self-healing behaviour of nanocomposite samples containing $\mathrm{CF}$ and $\mathrm{CNT}-\mathrm{OH}$ in the PU matrix was studied. After the first self-healing cycle, the strength recovery of 
nanocomposite samples up to $72 \%$ was achieved. The selfhealing level of nanocomposites was lower in comparison to neat PU-based samples. The lower healing ability of nanocomposites can be attributed to the reduction in mobility and diffusion of PU chains caused by the presence of carbon components. The healing capability of the nanocomposites expressed as an increase in the tensile strength after selfhealing of the damaged nanocomposites is greater than that for neat PU. The likely self-healing mechanism in nanocomposite is both partial rebuilding hydrogen bonds between PU chains in the damaged PU matrix and the formation of bonds between the surface of carbon components and the matrix. After healing, a greater fracture work recovery was obtained for samples containing both $\mathrm{CF}$ and $\mathrm{CNT}-\mathrm{OH}$ compared to the neat PU-based samples and samples containing CNT$\mathrm{OH}$. Due to the presence of carbon components characterized by a distinctly higher CTC in comparison to neat PU, the heat transfer from the environment, necessary to initiate the self-healing process, to the inner part of the nanocomposite samples, is more effective, which allows the use of this polymer to manufacture nanocomposite/composite samples with increased transverse dimensions. The results obtained proved that the self-healing process in the PU matrix modified with CNT-OH and CF is possible, and such carbon components create new possibilities in the fabrication of PUbased fibrous composite and nanocomposite materials.

\section{Data Availability}

The polyurethane formulation, mechanical results, thermal conductivity result, and self-regeneration test results data used to support the findings of this study are included within the article.

\section{Conflicts of Interest}

The authors declare that they have no conflict of interest.

\section{Acknowledgments}

The work was supported by the Polish National Centre for Research and Development, project no. DEC2012/05/N/ST8/03403.

\section{References}

[1] G. Sung and J. H. Kim, "Influence of filler surface characteristics on morphological, physical, acoustic properties of polyurethane composite foams filled with inorganic fillers," Composites Science and Technology, vol. 146, pp. 147-154, 2017.

[2] H. Khatoon and S. Ahmad, "A review on conducting polymer reinforced polyurethane composites," Journal of Industrial and Engineering Chemistry, vol. 53, pp. 1-22, 2017.

[3] P. Parandoush and D. Lin, "A review on additive manufacturing of polymer-fiber composites," Composite Structures, vol. 182, pp. 36-53, 2017.

[4] S. Y. Moon, J. K. Kim, C. Nah, and Y. S. Lee, "Polyurethane/montmorillonite nanocomposites prepared from crystalline polyols, using 1,4-butanediol and organoclay hybrid as chain extenders," European Polymer Journal, vol. 40, no. 8, pp. 1615-1621, 2004.

[5] M. Özgür Seydibeyoğlu and K. Oksman, "Novel nanocomposites based on polyurethane and micro fibrillated cellulose," Composites Science and Technology, vol. 68, no. 3-4, pp. 908-914, 2008.

[6] B. Yıldız, M. Ö. Seydibeyoğlu, and F. S. Güner, "Polyurethanezinc borate composites with high oxidative stability and flame retardancy," Polymer Degradation and Stability, vol. 94, no. 7, pp. 1072-1075, 2009.

[7] M. P. Stevens, Polymer Chemistry: An Introduction, Oxford University Press, Oxford, 1990.

[8] W. D. Callister, Materials Science and Engineering - An Introduction, John Wiley \& Sons. Inc, New York, 1994.

[9] T. Roberts, "Rapid growth forecast for carbon fibre market," Reinforced Plastics, vol. 51, no. 2, pp. 10-13, 2007.

[10] A. Jacob, “The popularity of carbon fibre," Reinforced Plastics, vol. 50, no. 3, pp. 22-24, 2006.

[11] Z. Zhou, X. Wang, S. Faraji, P. D. Bradford, Q. Li, and Y. Zhu, "Mechanical and electrical properties of aligned carbon nanotube/carbon matrix composites," Carbon, vol. 75, pp. 307-313, 2014.

[12] T. Windhorst and G. Blount, "Carbon-carbon composites: a summary of recent developments and applications," Materials and Design, vol. 18, no. 1, pp. 11-15, 1997.

[13] J. F. Su, E. Schlangen, and Y. Y. Wang, "Investigation the selfhealing mechanism of aged bitumen using microcapsules containing rejuvenator," Construction and Building Materials, vol. 85, pp. 49-56, 2015.

[14] T. Gumula and P. Szatkowski, "Regeneration efficiency of composites containing two-sized capillaries," Polymer Composites, vol. 37, no. 4, pp. 1223-1230, 2016.

[15] Y. Jialan, Y. Chenpeng, Z. Chengfei, and H. Baoqing, "Preparation process of epoxy resin microcapsules for self - healing coatings," Progress in Organic Coatings, vol. 132, pp. 440444, 2019.

[16] Y. C. Yuan, M. Z. Rong, M. Q. Zhang, J. Chen, G. C. Yang, and X. M. Li, "Self-healing polymeric materials using epoxy/mercaptan as the healant," Macromolecules, vol. 41, no. 14, pp. 5197-5202, 2008.

[17] W. H. Binder, "Self-healing polymers," Polymer, vol. 69, p. 215, 2015.

[18] J. O. Outwater and D. J. Gerry, "On the fracture energy, rehealing velocity and refracture energy of cast epoxy resin," The Journal of Adhesion, vol. 1, no. 4, pp. 290-298, 2006.

[19] W. Chian and D. C. Timm, "Chemical/mechanical analyses of anhydride-cured thermosetting epoxys: DGEBA/NMA/BDMA," Macromolecules, vol. 37, no. 21, pp. 80988109, 2004.

[20] C. T. Ho, "Reactive two-part polyurethane compositions and optionally self-healable and scratch-resistant coatings prepared therefrom," Google Patents, 1996, Australian Patent Office Patent no. 705850.

[21] S. Saini and D. Jain, "The effect of healing time on the selfhealing efficiency of carbon fibre reinforced polymer composites," Materials Today, vol. 4, no. 2, pp. 2903-2909, 2017.

[22] V. K. Thakur and M. R. Kessler, "Self-healing polymer nanocomposite materials: a review," Polymer, vol. 69, pp. 369383, 2015.

[23] P. Zhang and G. Li, "Advances in healing-on-demand polymers and polymer composites," Progress in Polymer Science, vol. 57, pp. 32-63, 2016. 
[24] M. A. L. Manchado, L. Valentini, J. Biagiotti, and J. M. Kenny, "Thermal and mechanical properties of single-walled carbon nanotubes-polypropylene composites prepared by melt processing," Carbon, vol. 43, no. 7, pp. 1499-1505, 2005.

[25] Y. C. Yuan, T. Yin, M. Z. Rong, and M. Q. Zhang, "Self healing in polymers and polymer composites. Concepts, realization and outlook: a review," Express Polymer Letters, vol. 2, no. 4, pp. 238-250, 2008.

[26] L. Feng, Z. Yu, Y. Bian, J. Lu, X. Shi, and C. Chai, "Self-healing behavior of polyurethanes based on dual actions of thermoreversible Diels-Alder reaction and thermal movement of molecular chains," Polymer, vol. 124, pp. 48-59, 2017.

[27] G. Williams, R. Trask, and I. Bond, "A self-healing carbon fibre reinforced polymer for aerospace applications," Composites Part A: Applied Science and Manufacturing, vol. 38, no. 6, pp. 1525-1532, 2007.

[28] S. Yang, X. du, S. Deng et al., "Recyclable and self-healing polyurethane composites based on Diels-Alder reaction for efficient solar-to-thermal energy storage," Chemical Engineering Journal, vol. 398, pp. 125654-128947, 2020.

[29] Y. Li, Z. Yang, J. Zhang et al., "Novel polyurethane with high self-healing efficiency for functional energetic composites," Polymer Testing, vol. 76, pp. 82-89, 2019.

[30] C. Lin, D. Sheng, X. Liu et al., "Effect of different sizes of graphene on Diels-Alder self-healing polyurethane," Polymer, vol. 182, article 121822, 2019.

[31] X. Xu, P. Fan, J. Ren et al., "Self-healing thermoplastic polyurethane (TPU)/polycaprolactone (PCL) /multi-wall carbon nanotubes (MWCNTs) blend as shape-memory composites," Composites Science and Technology, vol. 168, pp. 255-262, 2018.

[32] M. Liu, J. Zhong, Z. Li et al., "A high stiffness and self-healable polyurethane based on disulfide bonds and hydrogen bonding," European Polymer Journal, vol. 124, article 109475, 2020.

[33] B. Willocq, J. Odent, P. Dubois, and J. M. Raquez, “Advances in intrinsic self-healing polyurethanes and related composites," RSC Advances, vol. 10, no. 23, pp. 13766-13782, 2020.

[34] P. Szatkowski, K. Pielichowska, and S. Blazewicz, "Mechanical and thermal properties of carbon-nanotube-reinforced selfhealing polyurethanes," Journal of Materials Science, vol. 52, no. 20, pp. 12221-12234, 2017.

[35] F. L. Matthews and R. D. Rawlings, Composite Materials Engineering and Science, Chapman and Hall, London, 1994.

[36] K. T. Lau and D. Hui, "Effectiveness of using carbon nanotubes as nano-reinforcements for advanced composite structures," Carbon, vol. 40, no. 9, pp. 1605-1606, 2002.

[37] M. H. Al-Saleh and U. Sundararaj, "Review of the mechanical properties of carbon nanofiber/polymer composites," Composites Part A: Applied Science and Manufacturing, vol. 42, no. 12, pp. 2126-2142, 2011.

[38] A. F. Ismail and P. S. Goh, Carbon-Based Polymer Nanocomposites for Environmental and Energy Applications, Elsevier, 2018.

[39] M. Rahaman, D. Khastgir, and A. K. Aldalbahi, Carbon-Containing Polymer Composites, Springer, 2019.

[40] I. Balberg, "Percolation theory and its application in electrically conducting materials," in Semiconducting polymer composites, X. Yang, Ed., pp. 145-169, Wiley - VCH, 2013.

[41] C. Gayner and K. K. Kar, "Recent advances in thermoelectric materials," Progress in Materials Science, vol. 83, pp. 330$382,2016$.
[42] H. W. Siesler, "Structure-property relations in polymers, in vibrational spectroscopy of polymers," Advances in Chemistry, vol. 236, 87 pages, 1993.

[43] N. J. Everall, J. M. Chalmers, and P. R. Griffiths, Vibrational Spectroscopy of Polymers. Principles and Practice, John Wiley \& Sons, Chichester, 2007.

[44] C. Larosa, N. Patra, M. Salerno, L. Mikac, R. Merijs Meri, and M. Ivanda, "Preparation and characterization of polycarbonate/multiwalled carbon nanotube nanocomposites," Beilstein Journal of Nanotechnology, vol. 8, pp. 2026-2031, 2017.

[45] K. Pielichowska, S. Glowinkowski, J. Lekki, D. Binias, K. Pielichowski, and J. Jenczyk, "PEO/fatty acid blends for thermal energy storage materials, structural/morphological features and hydrogen interactions," European Polymer Journal, vol. 44, no. 10, pp. 3344-3360, 2008.

[46] T. Ji, Y. Feng, M. Qin, and W. Feng, "Thermal conducting properties of aligned carbon nanotubes and their polymer composites," Composites Part A Applied Science and Manufacturing, vol. 91, pp. 351-369, 2016.

[47] P. D. Bradford, X. Wang, H. Zhao, and Y. T. Zhu, "Tuning the compressive mechanical properties of carbon nanotube foam.," Carbon, vol. 49, no. 8, pp. 2834-2841, 2011.

[48] G. A. Kourouklis, J. Arvanitidis, D. Christofilos, and S. Ves, "High pressure Raman spectroscopy in carbon nanotubes," Acta Physica Polonica A, vol. 116, no. 1, pp. 13-18, 2009.

[49] L. Bokobza and J. Zhang, "Raman spectroscopic characterization of multiwall carbon nanotubes and of composites," Express Polymer Letter, vol. 6, no. 7, pp. 601-608, 2012.

[50] P. Musiol, P. Szatkowski, M. Gubernat, A. Weselucha-Birczynska, and S. Blazewicz, "Comparative study of the structure and microstructure of PAN-based nano- and micro-carbon fibers," Ceramics International, vol. 42, no. 10, pp. 11603 11610, 2016.

[51] D. G. Aggelis, N. M. Barkoula, T. E. Matikas, and A. S. Paipetis, "Acoustic structural health monitoring of composite materials : damage identification and evaluation in cross ply laminates using acoustic emission and ultrasonics," Composites Science and Technology, vol. 72, no. 10, pp. 1127-1133, 2012. 